\title{
Asset management using genetic algorithm: Evidence from Tehran Stock Exchange
}

\author{
Abbas Sarijaloo $^{\mathrm{a}}$ and Aliakbar Moradbakloo ${ }^{\mathrm{b}^{*}}$
}

${ }^{a}$ Department of Management and Accounting, Arak Branch, Islamic Azad University, Arak, Iran

${ }^{b}$ Masters Student, Department of Management and Accounting, Arak Branch, Islamic Azad University, Arak, Iran

C H R O N I C L E

\begin{tabular}{l}
\hline Article history: \\
Received June 28, 2013 \\
Received in revised format \\
19 October 2013 \\
Accepted 20 December 2013 \\
Available online \\
December 312013 \\
\hline Keywords: \\
Tehran Stock Exchange \\
Genetic algorithm \\
Asset Management
\end{tabular}

\section{A B S T R A C T}

This paper presents an empirical investigation to study the effect of market management using Markowitz theorem. The study uses the information of 50 best performers on Tehran Stock Exchange over the period 2006-2009 and, using Markowitz theorem, the efficient asset allocation are determined and the result are analyzed. The proposed model of this paper has been solved using genetic algorithm. The results indicate that Tehran Stock Exchange has managed to perform much better than average world market in most years of studies especially on year 2009. The results of our investigation have also indicated that one could reach outstanding results using GA and forming efficient portfolio.

\section{Introduction}

During the past few years, there have been tremendous works on the implementation of metaheuristics to solve many complicated portfolio optimization problems. Oh et al. (2005), for instance, proposed a portfolio optimization scheme for index fund management using genetic algorithm. They explained that Index fund could be one of popular strategies in portfolio management, which aims at matching the performance of the benchmark index such as the S\&P 500 in New York and the FTSE 100 in London as closely as possible and many fund managers have taken the strategy. Over the past decades, the performances of index funds were better than the ones actively managed mutual funds. Oh et al. (2005) reported that index fund could improve its performance more efficiently with the proposed GA portfolio scheme and they demonstrated the performance of their proposed GA model for index fund designed to track Korea Stock Price Index (KOSPI) 200. 
Chang et al. (2009) introduced a heuristic approach to portfolio optimization problems in variousrisk measures by applying GA method and compared its performance to mean-variance model in cardinality constrained efficient frontier. They collected three risk measures based on mean-variance by Markowitz; semi-variance, mean absolute deviation and variance with skewness. They showed that these portfolio optimization problems could now be solved by GA if mean-variance, semivariance, mean absolute deviation and variance with skewness were applied as the measures of risk. The robustness of the heuristic method was verified by three data sets collected from main financial markets. The empirical results indicated that the investors could include only one third of total assets into the portfolio, which outperforms than those contained more assets.

Skolpadungket et al. (2007) investigated a multi-objective portfolio optimization using GA method. Lin and Liu $(2005,2008)$ considered GA for portfolio selection problems with minimum transaction lots. Doerner et al. (2004) used Pareto ant colony optimization by considering a metaheuristic approach to multiobjective portfolio selection.

Maringer and Kellerer (2003) presented an optimization of cardinality constrained portfolios with a hybrid local search algorithm. They suggested a hybrid local search algorithm, which combined principles of Simulated Annealing and evolutionary strategies and it proved to highly efficiently approach such problem. Aranha and Iba (2009) presented a memetic tree-based genetic algorithm and its application to portfolio optimization.

Zitzler et al. (2000) provided a systematic comparison of different evolutionary approaches to multiobjective optimization using different test functions. Each test function involved a particular feature known to create difficulty in the evolutionary optimization process, primarily in converging to the Pareto-optimal solutions. By looking these various problem features separately, it is possible to see the type of problems may face.

Freitas et al. (2009) presented a new prediction-based portfolio optimization model, which captures short-term investment opportunities. They also applied neural network predictors to forecast stocks' returns and extracted a risk measure, based on the prediction errors, which have the same statistical foundation of the mean-variance model. The efficient diversification influences hold thanks to the selection of predictors with low and complementary pairwise error profiles. They used a large set of experiments with real data from the Brazilian stock market to test their portfolio optimization model, which included the evaluation of the Normality of the forecasting errors. The results indicated that it could be possible to calculated Normal prediction errors with non-Normal time series of stock returns and that the prediction-based portfolio optimization model could take advantage of short-term opportunities, outperforming the mean-variance model and beating the market index.

Fernandez-Rodriguez et al. (2005) investigated the profitability of a simple and very common technical trading rule used for the General Index of the Madrid Stock Market. The optimal trading rule parameter values were detected using a GA method. They reported that, for reasonable trading costs, the technical trading rule was always superior to a risk-adjusted buy-and-hold strategy.

\section{The proposed study}

Consider a portfolio optimization (Markowitz, 1952) problem where there are $n$ assets for investment, $\mu_{i}$ is the return of each asset, $i=1, \ldots, n$. In addition, let $H$ be the matrix of variance/covariance among $n$ different assets. The optimal solution of portfolio is determined as follows, 
$\min -t x^{\prime} \mu+\frac{1}{2} x^{\prime} H x$

subject to

$\sum_{i=1}^{n} x_{i}=1$

$L_{i} y_{i} \leq x_{i} \leq U_{i} y_{i}$

$\sum_{i=1}^{n} y_{i}=K$.

In this model, $t$ is an arbitrary positive parameter, which is used as a tradeoff between risk and reward. $\mathrm{L}_{\mathrm{i}}$ and $\mathrm{U}_{\mathrm{i}}$ represent lower and upper limits for each asset, $y_{i}$ is a binary variable, which is 1 if asset $i$ is selected and zero, otherwise, and finally $K$ determines the number of assets in the portfolio. The optimal solution of this problem, $x$, determines the portion of each asset in the portfolio. This is formal statement of Markowitz problem by considering cardinality problem, which is categorized as combinatorial optimization and there are several metaheuristics proposed to solve such problem (Chang et al., 2000, 2009; Maringer \& Kellerer, 2003; Cura, 2009). One of the most popular methods for solving such problem is to use genetic algorithm (GA) (Goldberg et al., 1988; Raymond \& Rousset, 1995; Michalewicz, 1996). The proposed model of this paper uses GA method to find efficient solution in different years. The study uses the information of 50 best performers on Tehran Stock Exchange over the period 2006-2009 and, using Markowitz theorem, the efficient asset allocation are determined and the result are analyzed.

\section{The results}

In this section, we present details of our findings on the performance of the proposed model and we compare the results with random search and equal weight methods. We first present the average return of the portfolio $\left(\mu_{p}=\mu^{\prime} x\right)$ and risk of the portfolio $\left(\sigma_{p}^{2}=x^{\prime} H x\right)$. Table 1 demonstrates the results of our findings in different years of study as follows,

\section{Table 1}

The results of portfolio in different years of study

\begin{tabular}{ccccc}
\hline Measure & 2006 & 2007 & 2008 & 2009 \\
\hline Return & 0.07693 & 0.16096 & 0.02193 & 0.52207 \\
Risk & 0.00506 & 0.00722 & 0.00979 & 0.01874 \\
\hline
\end{tabular}

As we can observe from the results of Table 1, Tehran Stock Exchange performed pretty well during the fiscal year of 2009 with an average return of 52\%, which was a remarkable return during the year of investment. In Iran, stock market normally goes under uncertainty when presidential election. However, this year was exception and despite the fact that a controversial election was happened but stock market responded positively on the incident. We have also compared the performance of stock market with Sharp ratio (Sharp, 1964, 2007) and Table 2 demonstrates the results of our survey.

Table 2

The summary of comparison of the proposed model versus Sharp ratio

\begin{tabular}{ccccc}
\hline & 2006 & 2007 & 2008 & 2009 \\
\hline The proposed model & 15.20167 & 22.30434 & 2.23893 & 27.86437 \\
Risk & -7.02167 & -3.38166 & -1.61056 & 0.73783 \\
\hline
\end{tabular}

Note that for the proposed model of this paper, we have adopted the existing GA code, which has already been used in other portfolio optimization applications and applied the same parameters. In addition, Fig. 1 shows the mean and the average distance between individuals of the proposed model in different years. 


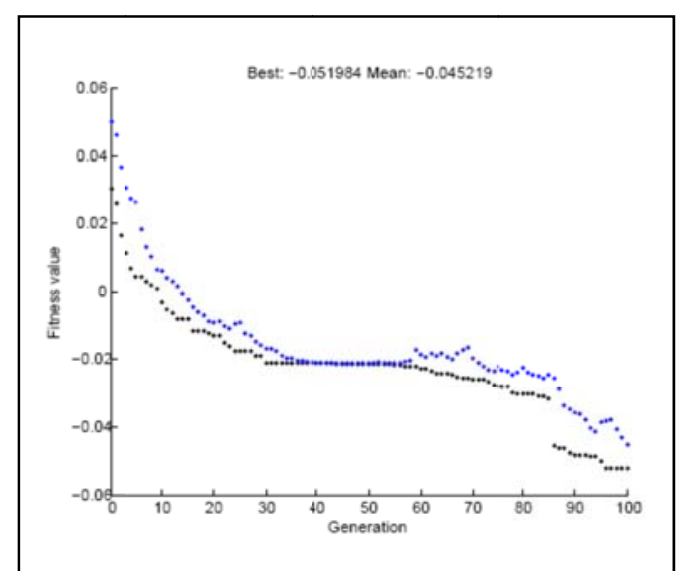

The mean of fitness value (2006)

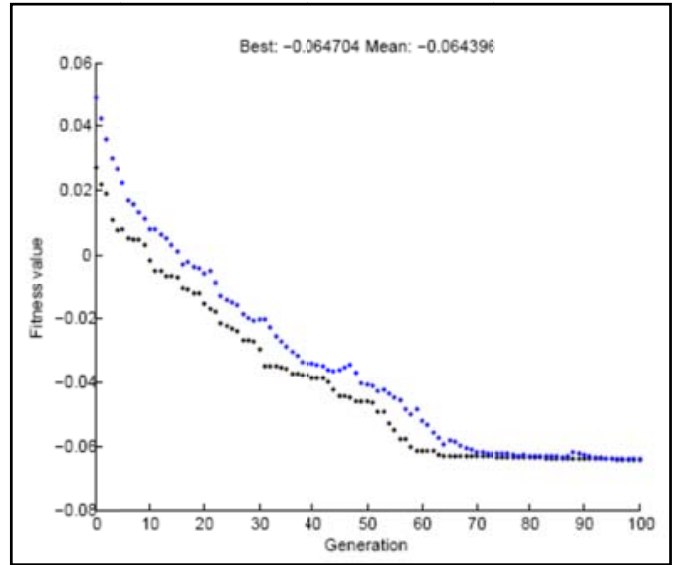

The mean of fitness value (2007)

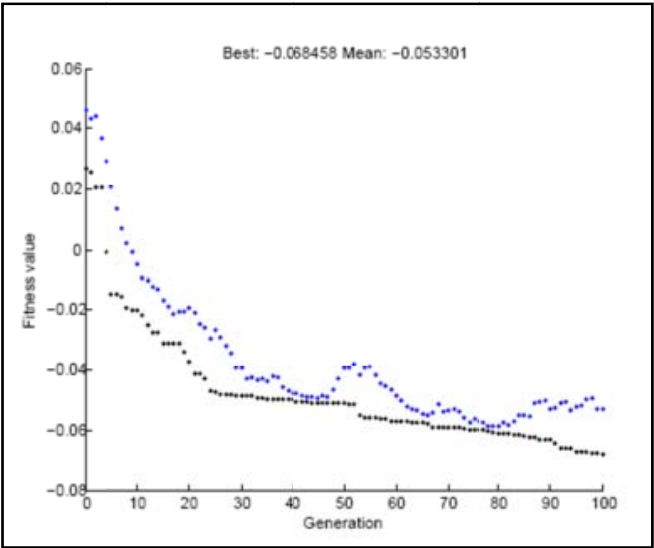

The mean of fitness value (2008)

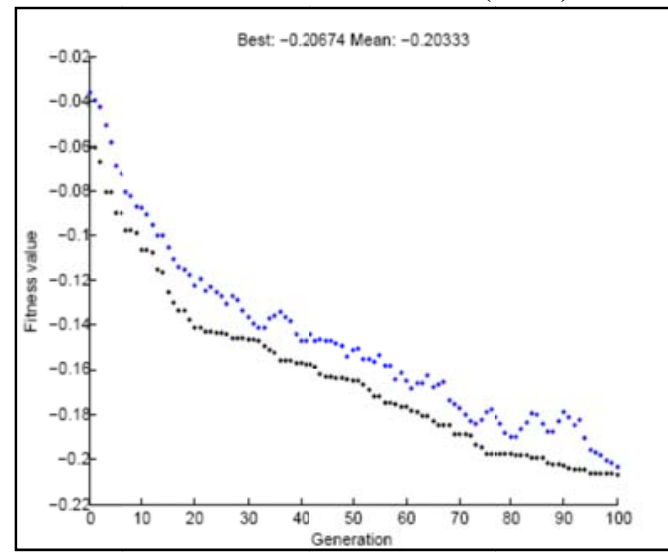

The mean of fitness value (2008)

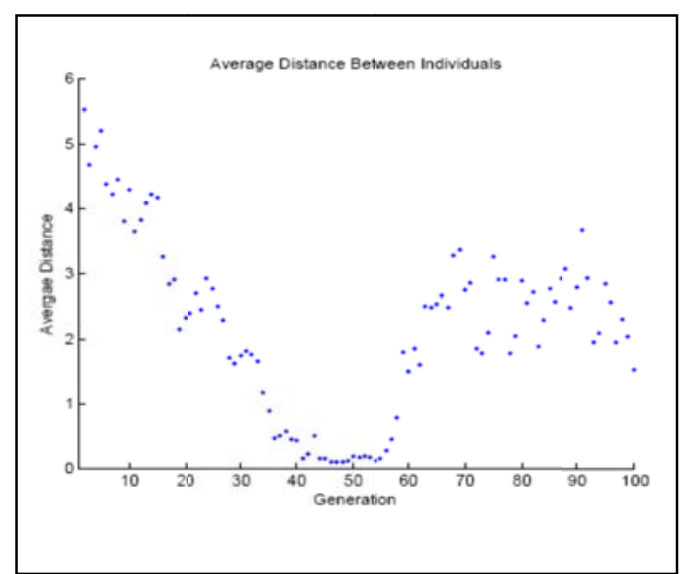

The average distance between individuals (2006)

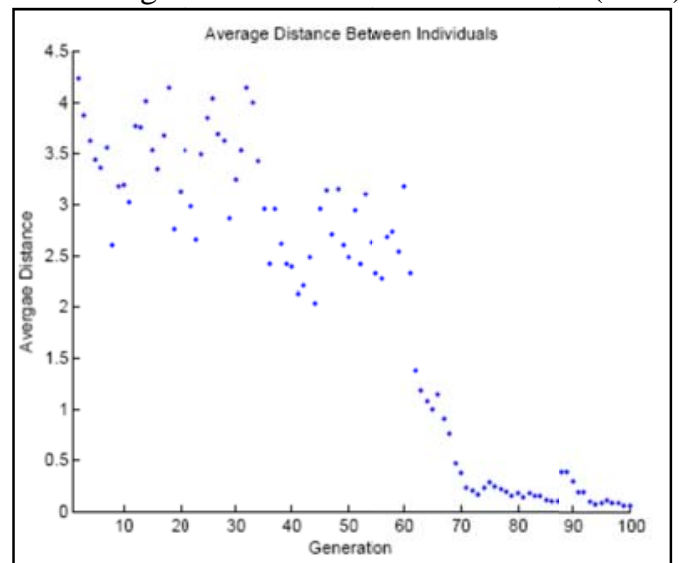

The average distance between individuals (2007)

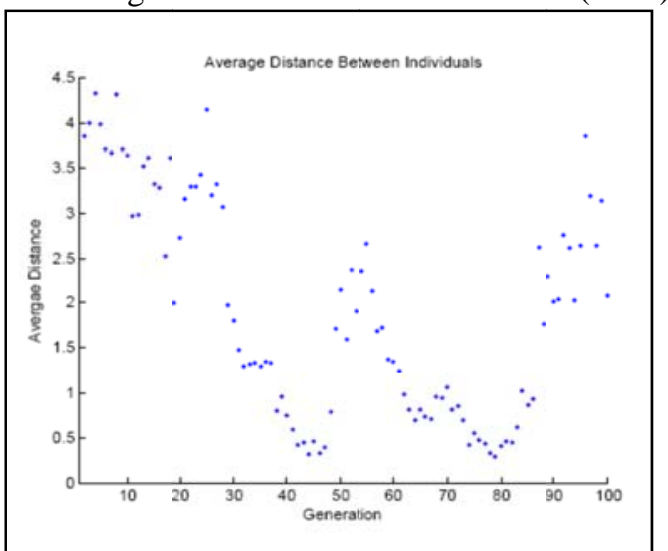

The average distance between individuals (2008)

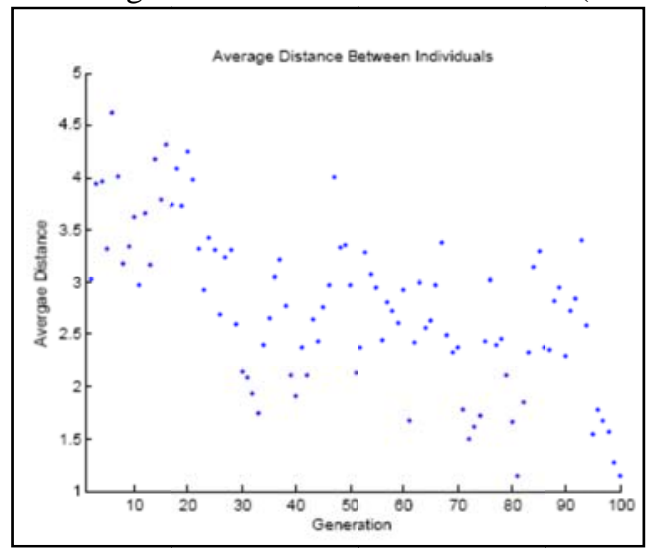

The average distance betwieen individuals (2008)

Fig. 1. The mean of fitness value and the average distance between individuals 


\section{Discussion and conclusion}

One of the primary concerns on portfolio optimization is to find appropriate assets mix to reach maximum return with minimum risk. In this paper, we have presented an empirical investigation on the implementation of genetic algorithm to solve portfolio optimization with cardinality constrains. The proposed model of this paper has been applied on 50 best performers of Tehran Stock Exchange over the period 2006-2009 and the performance of the stock market has been compared with Sharp ratio. The results of our investigation have indicated that the proposed model of this paper could determine the best combination of the best performers with promising average return. Note that using GA to solve combinatorial optimization problems does not guarantee to reach global solution and we recommend interested researchers to use another techniques and compare the performance of their methods with GA method.

\section{Acknowledgement}

The authors would appreciate the comments made on earlier version of this paper, which has significantly improved the quality of the paper.

\section{References}

Aranha, C., \& Iba, H. (2009). The memetic tree-based genetic algorithm and its application to portfolio optimization. Memetic Computing, 1(2), 139-151.

Chang, T. J., Meade, N., Beasley, J. E., \& Sharaiha, Y. M. (2000). Heuristics for cardinality constrained portfolio optimisation. Computers \& Operations Research, 27(13), 1271-1302.

Chang, T. J., Yang, S. C., \& Chang, K. J. (2009). Portfolio optimization problems in different risk measures using genetic algorithm. Expert Systems with Applications, 36(7), 10529-10537.

Cura, T. (2009). Particle swarm optimization approach to portfolio optimization. Nonlinear Analysis: Real World Applications, 10(4), 2396-2406.

Doerner, K., Gutjahr, W. J., Hartl, R. F., Strauss, C., \& Stummer, C. (2004). Pareto ant colony optimization: A metaheuristic approach to multiobjective portfolio selection. Annals of Operations Research, 131(1-4), 79-99.

Fernandez-Rodriguez, F., Gonzalez-Martel, C., \& Sosvilla-Rivero, S. (2005). Optimization of technical rules by genetic algorithms: evidence from the Madrid stock market. Applied Financial Economics, 15(11), 773-775.

Freitas, F. D., De Souza, A. F., \& de Almeida, A. R. (2009). Prediction-based portfolio optimization model using neural networks. Neurocomputing, 72(10), 2155-2170.

Goldberg, D. E., \& Holland, J. H. (1988). Genetic algorithms and machine learning. Machine learning, 3(2), 95-99.

Lin, D., Li, X., \& Li, M. (2005). A genetic algorithm for solving portfolio optimization problems with transaction costs and minimum transaction lots. Advances in Natural Computation (pp. 808-811). Springer Berlin Heidelberg.

Lin, C. C., \& Liu, Y. T. (2008). Genetic algorithms for portfolio selection problems with minimum transaction lots. European Journal of Operational Research, 185(1), 393-404.

Markowitz, H. (1952). Portfolio selection. The journal of finance, 7(1), 77-91.

Maringer, D., \& Kellerer, H. (2003). Optimization of cardinality constrained portfolios with a hybrid local search algorithm. OR Spectrum, 25(4), 481-495.

Michalewicz, Z. (1996). Genetic algorithms + data structures= evolution programs. springer.

Oh, K. J., Kim, T. Y., \& Min, S. (2005). Using genetic algorithm to support portfolio optimization for index fund management. Expert Systems with Applications, 28(2), 371-379.

Raymond, M., \& Rousset, F. (1995). GENEPOP (version 1.2): population genetics software for exact tests and ecumenicism. Journal of heredity, 86(3), 248-249.

Sharpe, W. (1964). Capital asset prices: A theory of market equilibrium under conditions of risk. Journal of Finance, 19, 425-442. 
Sharp, Z. (2007). Principles of stable isotope geochemistry (p. 344). Upper Saddle River, NJ, USA: Pearson Education.

Skolpadungket, P., Dahal, K., \& Harnpornchai, N. (2007, September). Portfolio optimization using multi-objective genetic algorithms. In Evolutionary Computation, 2007. CEC 2007. IEEE Congress on (pp. 516-523). IEEE.

Zitzler, E., Deb, K., \& Thiele, L. (2000). Comparison of multiobjective evolutionary algorithms: Empirical results. Evolutionary computation, 8(2), 173-195. 